\title{
The Role of Construction Technology Techniques in Improving the Performance of Contemporary Housing Complexes, Bismayah City in Iraq: A Case Study
}

\author{
Safaaaldeen Hussein Ali ${ }^{1, *}$, Marwa Mohammed Kassid AL-Zaid ${ }^{2}$ \\ ${ }^{1}$ Department of Architectural Engineering, University of Technology, Iraq \\ ${ }^{2}$ Ministry of Electricity, Iraq
}

Received September 13, 2021; Revised January 11, 2022; Accepted February 28, 2022

\section{Cite This Paper in the following Citation Styles}

(a): [1] Safaaaldeen Hussein Ali, Marwa Mohammed Kassid AL-Zaid, "The Role of Construction Technology Techniques in Improving the Performance of Contemporary Housing Complexes, Bismayah City in Iraq: A Case Study," Civil Engineering and Architecture, Vol. 10, No. 2, pp. 531-543, 2022. DOI: 10.13189/cea.2022.100212.

(b): Safaaaldeen Hussein Ali, Marwa Mohammed Kassid AL-Zaid (2022). The Role of Construction Technology Techniques in Improving the Performance of Contemporary Housing Complexes, Bismayah City in Iraq: A Case Study. Civil Engineering and Architecture, 10(2), 531-543. DOI: 10.13189/cea.2022.100212.

Copyright $\bigcirc 2022$ by authors, all rights reserved. Authors agree that this article remains permanently open access under the terms of the Creative Commons Attribution License 4.0 International License

\begin{abstract}
Building methods have advanced because of technological development. So-called contemporary construction technology techniques have made construction processes faster, less expensive, and better performing, especially in the case of low-cost contemporary housing projects in Iraq, where these techniques have been developed by planning engineering solutions that fill the housing need in Iraq. This research aims to improve the formal, functional, and environmental requirements through contemporary construction technology techniques in housing complexes in Iraq. Solving the problem necessitated the adoption of a multistage analytical and descriptive approach. The first stage was to extract and create a theoretical framework for the subject. In the second stage, we applied it to the Bismayah housing project in Iraq to determine the most important terms approved in it. Finally, we analyze and discuss the results of the practical study.
\end{abstract}

Keywords Construction Technology Techniques, Performance Improvement, Contemporary Housing Complexes

\section{Introduction}

The concept of construction technology aims to clarify the use of technology and construction for buildings, where technology is defined as a way of thinking and solving problems. This way of thinking about the use of knowledge, information, and skills leads individuals to the desired results. It thus aims to satisfy humans' needs and increase their capabilities. Indeed, the optimal use of scientific knowledge as well as its application and adaptation can serve humans and improve their well-being [1]. Construction is defined as "the part related to the design of the structural fabric and how its components are put together" and is based on three issues: materials, construction methods, and systems [2]. Construction is linked to several factors such as (i) the number of pieces to be connected; (ii) the connection joints; (iii) the place of the assembly of the standardized, ready-made structural elements in the case of on-site installation and assembly of materials in the case of the on-site construction of buildings; and (vi) the construction time and materials [3], where the construction items consist of building materials and technical systems [2]. The construction process is based on the materials and methods used according to the nature of the construction system followed. Accordingly, this research aims to identify the factors for achieving efficient performance in the Bismayah city project through construction technology techniques (hollow core slab system).

\section{Research methodology:}

1. Creating a theoretical framework with a variety of relevant concepts. 
2. Extracting the main terms, their variables, and possible values to build the theoretical framework through a theoretical proposal of the role of construction technology in improving the functional performance of the Bismayah city project.

3. Studying and analyzing selected contemporary architectural application samples, in which construction technology techniques were used to improve their functional performance to implement the theoretical framework items.

4. Presenting the results, conclusions, and recommendations.

\section{Literature Review}

\subsection{Modern Methods of Construction Technology}

Modern construction technology is a term newly coined in the 21 st century for the several construction methods that differ from "traditional" construction methods carried out off-site such as factory building and prefabrication [2]. Comprising repeating units, structures, and ready-made elements, these methods developed with proper planning and design reduce construction time and cost and maintain the overall sustainability of the project [4]. Since many of these methods are formulated in the factory, they have also been called off-site, meaning that they are manufactured outside the construction site [5]. Modern construction technology dates to the post-Second World War period when prefabricated construction techniques spread because of the need to build a large number of houses after city buildings were destroyed during the war [4]. Their work stopped in the mid-1970s due to the problems that resulted from their poor design. Many of these buildings were built within the framework of projects that aimed to adopt economical methods and quick implementation as well as follow building methods with strict construction and economical standards that limited the intervention of architectural design. This was at the expense of achieving designs that considered the human aspects of the population. Because the repetition of the units and structural elements that comprise the buildings is exaggerated, their shapes and sizes are repeated in a way that makes them boring, both visually and in their use [5]. These methods were returned to at the beginning of the 21 st century because they aim to develop a building industry based on being economical and consider the human aspects of the population as well as the latest developments in architectural design in terms of sustainability, techniques, and new design experiences [3]. The most important elements are achieving diversity in the design of buildings that use industrial building systems, which require a formal repetition of their elements and prefabricated units, to achieve rapid construction and addressing the labour shortage that resulted from migration in the construction sector [5].
In the first stage of architectural design, designers rediscovered these modern methods. Although they stemmed from prefabrication methods, they differed because they were linked to economical standards and new technologies [2]. The main two advantages of modern construction technology techniques are achieving high levels of quality through factory-controlled assembly and achieving better levels of efficiency, resulting in reduced construction and delivery times. The most important modern construction techniques are as follows [5]

A. Prefabricated panels: This technology used to manufacture floors and walls is not performed on the work site, but rather prepared in advance in the factory (2D) and then transferred to the construction site and assembled there in three dimensions according to the plan. This method is highly effective for construction operations that contain many walls and floors. The prefabricated panels contain all building finishes such as insulation, windows, and doors [3].

B. 3D construction: The 3D building system depends on pre-designed independent building units completely built in the factory and then transferred to the worksite for assembly. These units can be a building or an integrated building that contains all internal and external finishes. This system can also be utilized in projects that contain duplicate blocks [5].

C. Hybrid construction (2D and 3D): This contains the first and second types to form an integrated structure [3].

\subsection{Role of Construction Technology Techniques in Improving the Performance of Buildings}

Construction technology techniques improve the performance of buildings by help raising the aesthetic, functional, and environmental performance of buildings as follows.

\subsubsection{Formal performance}

This is achieved by obtaining the aesthetic aspects in the level of design in each of the following [6]:

- The geometric shape of the housing unit.

- The shape of the building block.

The façades.

\subsubsection{Job performance}

This is achieved through achieving planning and design efficiency as follows.

\subsubsection{Planning efficiency:}

This is achieved by linking the house with the local environment, and it includes the following considerations [7]:

A. Respectful design of the site's characteristics [8]: 
- Integration between site planning and public transportation.

- Versatile development.

- Integration and interconnection between housing units.

- Availability of site services.

B. Compatibility of the design with the climate [7]:

- This is represented by the orientation of the building within the site, orientation of the rooms and windows, size of the windows, and possibility of benefiting from the characteristics of the building by using renewable energies such as solar energy.

- Compatibility between the building and site in terms of soil, terrain, and others. The design must be resistant to the conditions surrounding the site, such as choosing the appropriate construction materials and conditions to which the building is exposed according to the environment in which the building is constructed.

C. Connection of the design with the culture of the place:

This is achieved by using local materials, local labour, and local techniques as well as arts and crafts in the design.

\subsubsection{Design efficiency}

Functional efficiency is achieved by obtaining design efficiency in the following aspects.

\section{1) Functional unit designs:}

Functional efficiency is achieved by matching the spaces and their uses without wasting space. The necessary flexibility must be provided for future extensions. This takes place during the three phases of the project life cycle, namely, design, implementation, and occupancy and maintenance [6].

A. Design stage:

- Adopting design techniques (size and capacity of housing units, better orientation of buildings, reduced energy consumption, and reduced costs (construction costs, housing unit costs, building materials, and labour rates).

- Adopting construction technology (structural properties such as prefabricated buildings, building material properties, recyclability, thermal insulation, fire resistance).

- Using project information modelling (BIM): This is the process of creating digital models of the building, providing accurate information for the sustainable design process, and facilitating decision-making during the early design stages to improve the main performance outputs, such as [9]:

- Using energy effectively, making cost savings, and implementing renewable energy sources [8].

- Enhancing environmental and structural design by matching design variables with building performance using simulation and proactive structural analysis and conducting evolutionary structural improvement (making design a non-linear process) to improve building sustainability strategies and their performance [9].

- Adopting a participatory design environment through the organization and management of information and integration of computer applications.

B. Construction stage:

- Enhancing implementation by improving engineering participation and detecting conflicts.

- Building planning systems, site logistics and management.

- Choosing sustainable materials.

- Reducing material waste.

C. Operating stage:

- Using BIM to create a rich information database, constantly update it, and forecast emergencies.

- Managing the facility.

- Raising the quality of services.

- Maintaining infrastructure, security of the facility [4].

2) The grouping pattern of housing units:

A. The compatibility of grouping pattern with family's size.

B. The conformity of the grouping pattern to customs and traditions.

C. The compatibility of the grouping pattern with the achievement of social communication [6].

\subsubsection{Environmental performance}

This means the principles of sustainable housing design, which can be summarized as follows.

1) Efficient handling of energy:

A. Selecting the site accurately: The dwelling provides a high-quality internal environmental by providing comfortable elements for residents and responding to site determinants [9].

B. Designing the building's envelope to be compatible with the climate: This includes the use of natural systems such as solar energy, ventilation, and natural lighting [6].

C. Orienting the housing unit: This includes the geometric shape of the housing unit, size of the openings, nature of the building materials used, and location of the residential building relative to neighbouring buildings.

D. Raising the efficiency of operating systems technology: Avoiding wasting energy and using clean technology (i.e., moving away from toxic emissions from materials).

E. Developing local technologies for energy production. 
2) Efficient handling of materials:

A. Using local materials on the site: The use of local materials is characterized by reducing the energy and effort required to manufacture and transport materials to the construction site [8].

B. Using materials compatible with the local climate: This increases the performance efficiency of the dwelling and reduces construction costs [6].

C. Using economic technologies to deal with materials by

- Reducing the quantities of construction materials.

- Increasing the use of recycled materials.

- Reducing waste generated from the construction. [9]

D. Using materials compatible with local labour: by using local materials compatible with the local labour accustomed to working with them or by reusing materials from old buildings in nearby locations to reduce production costs [6].

3) Efficient handling of water [8]:

A. Reducing the water needed to coordinate the site.

B. Improving and developing water technology.

C. Raising awareness of the efficient use of water and improving the behaviour of dealing with it.

\section{General Application Framework}

\subsection{Theoretical Framework}

The theoretical framework of the research is formulated from the indicators drawn from the foregoing propositions and categorized into four main terms, as shown in Table 1.

Table 1. Terms of the theoretical framework of the research (prepared by the researchers)

\begin{tabular}{|c|c|c|c|c|c|}
\hline Main item & Sub-item & \multicolumn{3}{|c|}{ Possible values } & Code \\
\hline \multirow{5}{*}{$\begin{array}{c}\text { Formal } \\
\text { performance } \\
\text { X.1 }\end{array}$} & \multirow{2}{*}{$\begin{array}{c}\text { The shape of the } \\
\text { housing unit } \\
\text { X.1.1 }\end{array}$} & \multicolumn{3}{|c|}{ The size and capacity of housing units } & X.1.1.1 \\
\hline & & \multicolumn{3}{|l|}{ Privacy } & X.1.1.2 \\
\hline & \multirow{3}{*}{$\begin{array}{c}\text { The shape of the } \\
\text { building block and } \\
\text { facades } \\
\text { X.1.2 }\end{array}$} & \multicolumn{3}{|c|}{ The form of the grouping style of housing units (visual enrichment) } & X.1.2.1 \\
\hline & & \multicolumn{3}{|c|}{ The design of the outer envelope of buildings } & X.1.2.2 \\
\hline & & \multicolumn{3}{|c|}{ Building materials and colours } & X.1.2.3 \\
\hline \multirow{13}{*}{$\begin{array}{l}\text { Functional } \\
\text { performance } \\
\text { X.2 }\end{array}$} & \multirow{3}{*}{$\begin{array}{c}\text { Planning efficiency } \\
\text { X.2.1 }\end{array}$} & \multicolumn{3}{|c|}{ The respective design for the site features } & X.2.1.1 \\
\hline & & \multicolumn{3}{|c|}{ The compatibility of the design with the environment } & X.2.1.2 \\
\hline & & \multicolumn{3}{|c|}{ The design is linked to the culture of the place } & X.2.1.3 \\
\hline & \multirow{10}{*}{$\begin{array}{l}\text { Design efficiency } \\
\text { X.2.2 }\end{array}$} & \multirow{6}{*}{ Design stage } & \multicolumn{2}{|l|}{ Design flexibility } & X.2.2.1 \\
\hline & & & \multicolumn{2}{|c|}{ The ability for future extension } & $X .2 .2 .2$ \\
\hline & & & \multicolumn{2}{|c|}{ Digital modelling and proactive structural analysis } & X.2.2.3 \\
\hline & & & \multicolumn{2}{|c|}{ Evolutionary structural optimization } & X.2.2.4 \\
\hline & & & \multirow{2}{*}{$\begin{array}{l}\text { Using BIM informational } \\
\text { modelling }\end{array}$} & $\begin{array}{l}\text { Enhancing the environmental and } \\
\text { structural design }\end{array}$ & X.2.2.5 \\
\hline & & & & $\begin{array}{l}\text { Adopting a participatory design } \\
\text { environment }\end{array}$ & X.2.2.6 \\
\hline & & \multirow{2}{*}{$\begin{array}{l}\text { Construction } \\
\text { stage }\end{array}$} & \multicolumn{2}{|c|}{ Building planning systems and site logistics and management } & X.2.2.7 \\
\hline & & & \multicolumn{2}{|c|}{ Choosing sustainable materials and reducing waste } & X.2.2.8 \\
\hline & & \multirow{2}{*}{ Operation stage } & \multicolumn{2}{|c|}{ Using BIM (database, update, and emergency forecast) } & X.2.2.9 \\
\hline & & & \multicolumn{2}{|c|}{ Maintaining the infrastructure and the safety and security of the facility } & X.2.2.10 \\
\hline \multirow{3}{*}{$\begin{array}{c}\text { Environmental } \\
\text { performance } \\
\text { X.3 }\end{array}$} & \multirow{3}{*}{$\begin{array}{c}\text { Harmony with the } \\
\text { local environment } \\
\text { and climate } \\
\text { efficiency } \\
\text { X.3.1 } \\
\end{array}$} & \multicolumn{3}{|c|}{ Efficient handling of energy } & X.3.1.1 \\
\hline & & \multicolumn{3}{|c|}{ Efficient handling of materials } & X.3.1.2 \\
\hline & & \multicolumn{3}{|c|}{ Efficient handling of water } & X.3.1.3 \\
\hline & Economic & Reducing energy & consumption & & X.4.1.1 \\
\hline & X.4.1 & $\begin{array}{l}\text { Reducing constr } \\
\text { labour }\end{array}$ & action costs, housing unit co & ts, and wage rates for building materials and & X.4.1.2 \\
\hline & & Using constructi & on technology in structural $\mathrm{r}$ & anufacturing & X.4.2.1 \\
\hline $\begin{array}{l}\text { material aspects } \\
\text { X.4 }\end{array}$ & Material & \begin{tabular}{|l} 
Studying the beh \\
building materia
\end{tabular} & $\begin{array}{l}\text { aviour and properties of } \\
\text { s }\end{array}$ & $\begin{array}{l}\text { Recyclability, heat insulation, fire } \\
\text { resistance }\end{array}$ & X.4.2.2 \\
\hline & X.4.2 & Structural behav & our testing and structural st & ength and toughness & X.4.2.3 \\
\hline & & $\begin{array}{l}\text { Choosing an adv } \\
\text { system and smar }\end{array}$ & $\begin{array}{l}\text { anced building material acc } \\
\text { t materials }\end{array}$ & rding to the structural characteristics of the & X.4.2.4 \\
\hline
\end{tabular}




\subsection{Practical Applications}

The Bismayah city project, one of the most important housing projects with technical applications in the field of housing, is selected. The project includes new developmental design imprints that confirm the spread of these modern technologies and their role in improving the performance of these projects. Moreover, the construction methods vary between structural frames and repeated units.

\subsubsection{Bismayah City Project}

The project is in the southeast of Baghdad, Iraq. The number of housing units is 100,000 units and these include 834 buildings with a height of 10 floors. The project includes all the social and technical infrastructure, see Figure 1. The design has moved away from the local character by adopting the multi-family pattern, which is considered as a positive characteristic for solving the housing crisis in Iraq [6], The interaction between the architectural design and environmental planning is achieved, as possible treatments are used to direct the residential buildings and public buildings, such as using sunshades to protect from direct sunlight. The housing empowerment in the project was achieved by using a pre-cast concrete method, which reduces production costs in the construction industry, as the project site was equipped with a sophisticated factory. This factory for pre-casting building items, the first of its kind in the Middle East, achieves the highest structural strength with less weight and more length [10].

These parts gave the project the advantage of high design flexibility in the housing unit by adopting a structural technique that helps raise the internal partitions without being bound by the structural frame of the building as a whole. This enabled the realization of spatial diversity in three types of housing $(100,120$, and $140 \mathrm{~m} 2)$ [6] as well as eased adopting the same design in both eastern and western designs, the difference between which is the addition or deletion of internal partitions. A typical measurement of space dimensions was adopted to reduce materials and time, raise comfort and safety, reduce the environmental impact (e.g., by using insulation in the facility) [10], respect the site through hierarchy, securing connections, easing access (convergence), raising the urban value, and achieving diversity and cohesion for different activities and housing as well as high densities of land investment efficiently [6].

\subsubsection{Residential Complex Planning in Bismayah}

The area of the Bismayah residential complex is about 1,830 hectares. This complex is designed to accommodate about 600,000 people with 100,000 housing units. An infrastructure network for the main streets, water, and electricity will be established in addition to public utilities developed by the Iraqi government, including commercial, recreational, and educational facilities as well as sewage and water treatment plants [12], as shown in Figure 2.

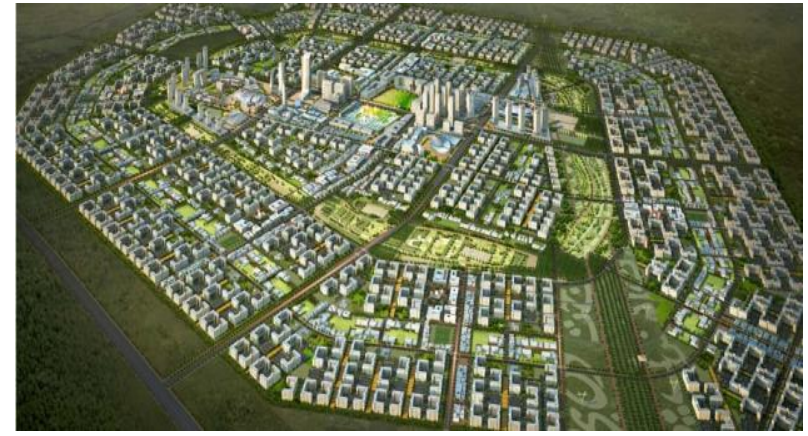

Figure 1. Aerial view of the Bismayah residential project [11]

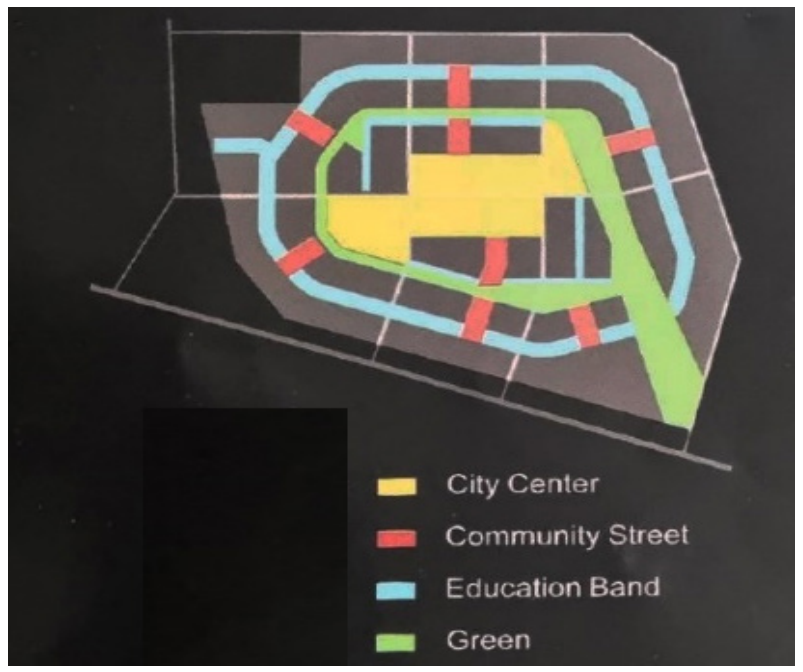

Figure 2. Land use in the residential complex [13]

The new city of Bismayah will be one of the newest cities in Iraq. Implementation started in 2013 and about $28 \%$ of the work has been completed. The project consists of eight sectors, each of which divided into several blocks [12], as shown in Figures 3-5.

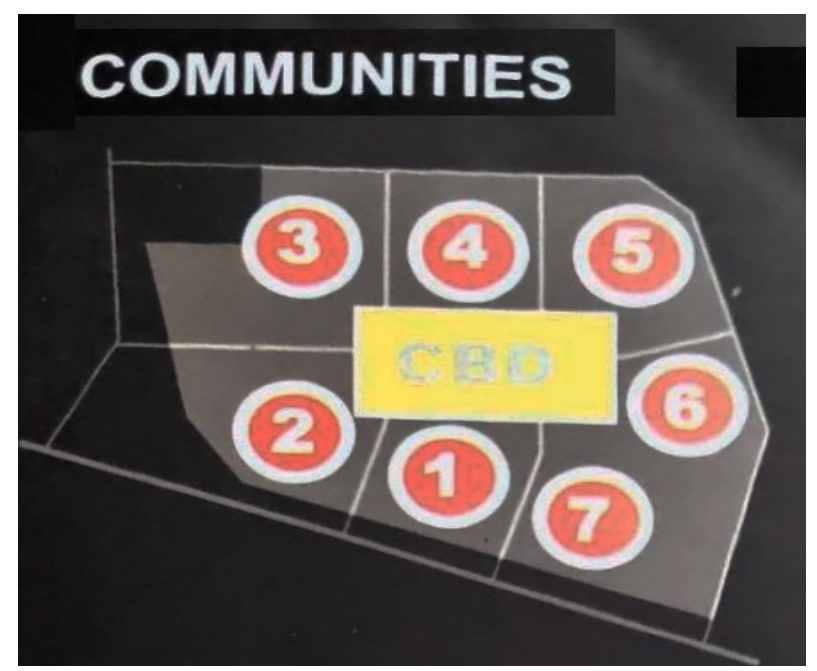

Figure 3. Main sectors in the Bismayah complex [13] 


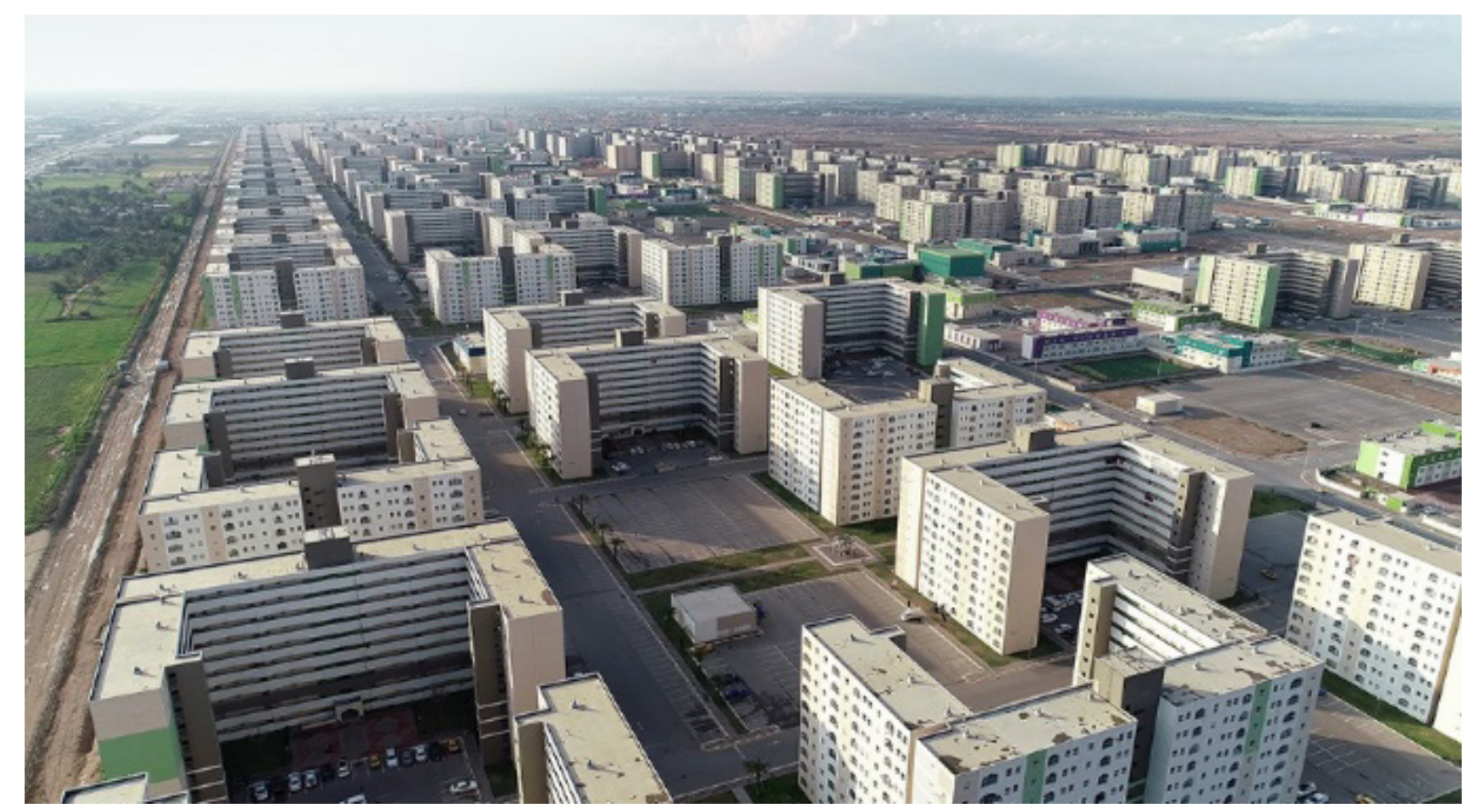

Figure 4. Division of residential units and open spaces [14]

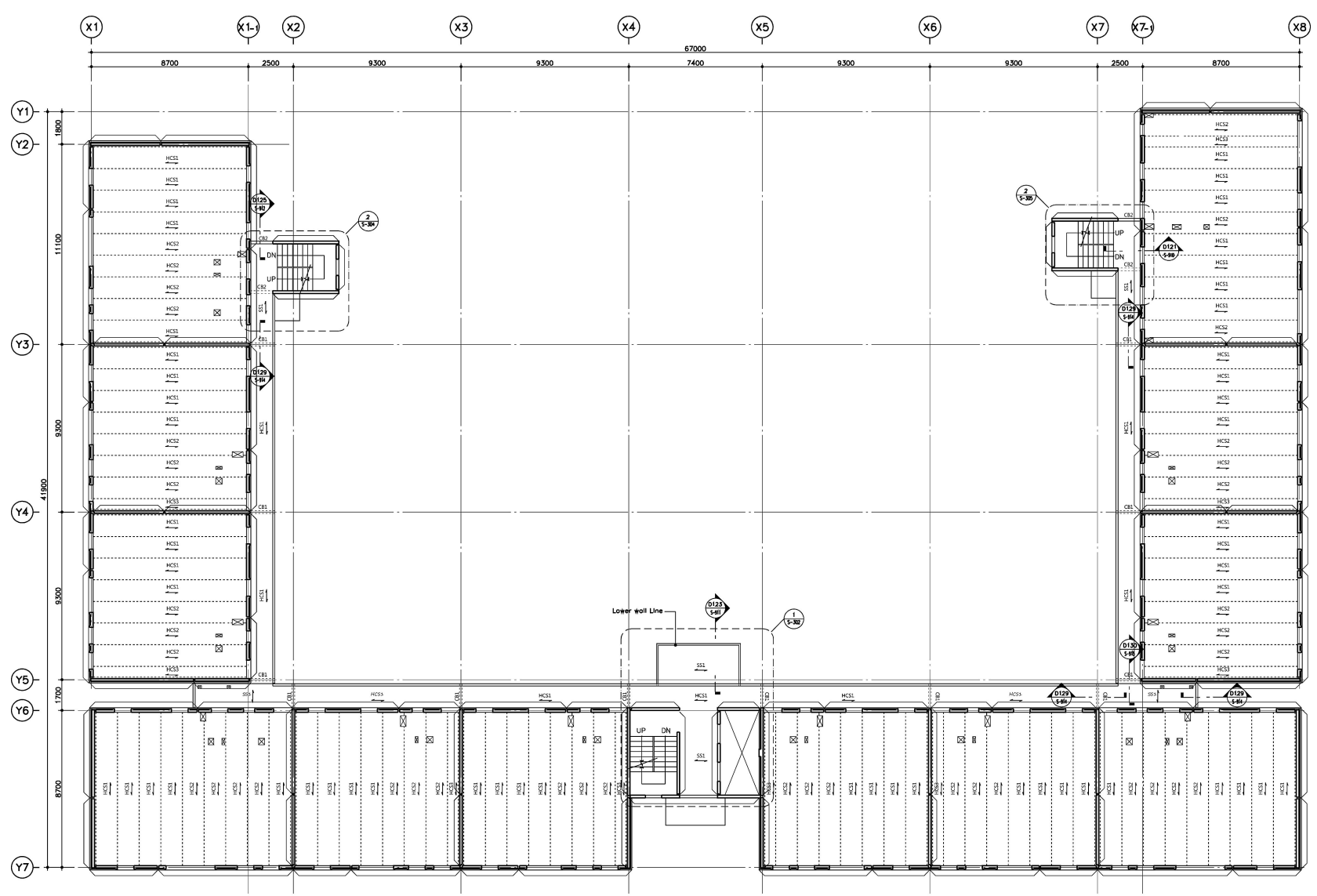

(1) 2ND FLOOR STRUCTURAL PLAN (101)

Figure 5. The layout of the first floor of a residential building in the project shows the diversity of unit areas in the three types $\left(100,120\right.$, and $\left.140 \mathrm{~m}^{2}\right)$ within the same building by using repeated pre-cast pieces [10] 


\subsubsection{Flexibility of the Interior Design of the Building Units in the Residential Complex}

Flexibility is nature's primary method of adapting to changing circumstances in conjunction with constant changes in human life and inhabitants' needs in the face of technological development. Various approaches to flexibility in architecture and housing have aimed to match the rate of change in contemporary life. Contemporary advances in building techniques have led to the freedom of walls as non-bearing elements and formation of so-called "open plan" designs. The modular system is a flexible approach to architecture, minimizing structural elements and making other parts mutable. The use of prefab technology also saves time, improves speed, and economic construction to produce building components in the factory and link them to suit future changes. The flexible connections between prefabricated units also allow linking or separating them from new needs to implement the concept of flexibility [15], [16], as shown in Figures 6 and 7.

\subsection{Practical Application in Research Samples:}

Here, by using the theoretical framework, multiple indicators are applied to the selected sample to obtain the verification results as well as discuss and analyse them (see appendix).

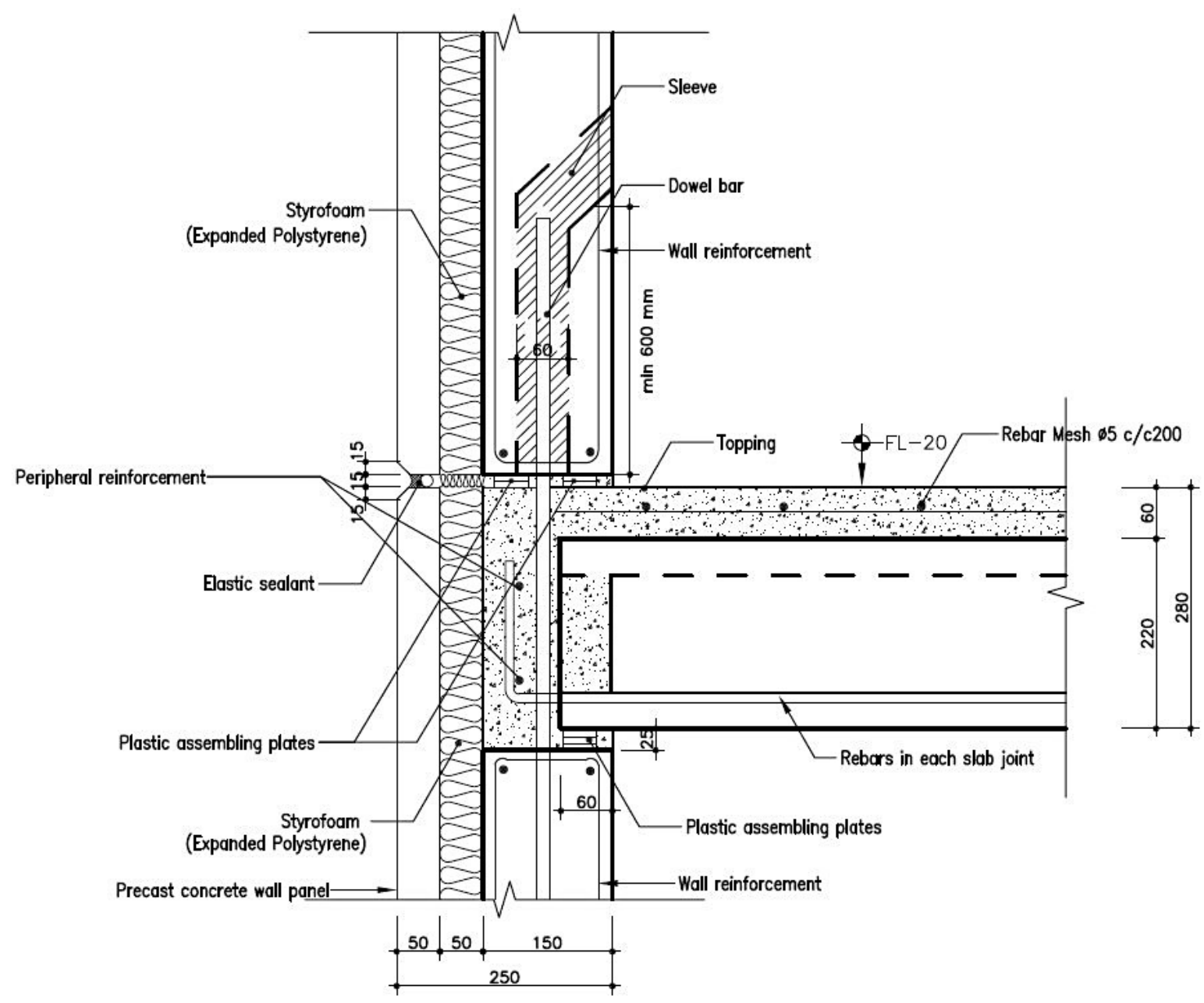

Figure 6. A - Longitudinal section detailing the bonding point between the pre-cast structural pieces of the interior corridor and sandwich wall and the simplified bonding structural technique that facilitates design flexibility [10] 


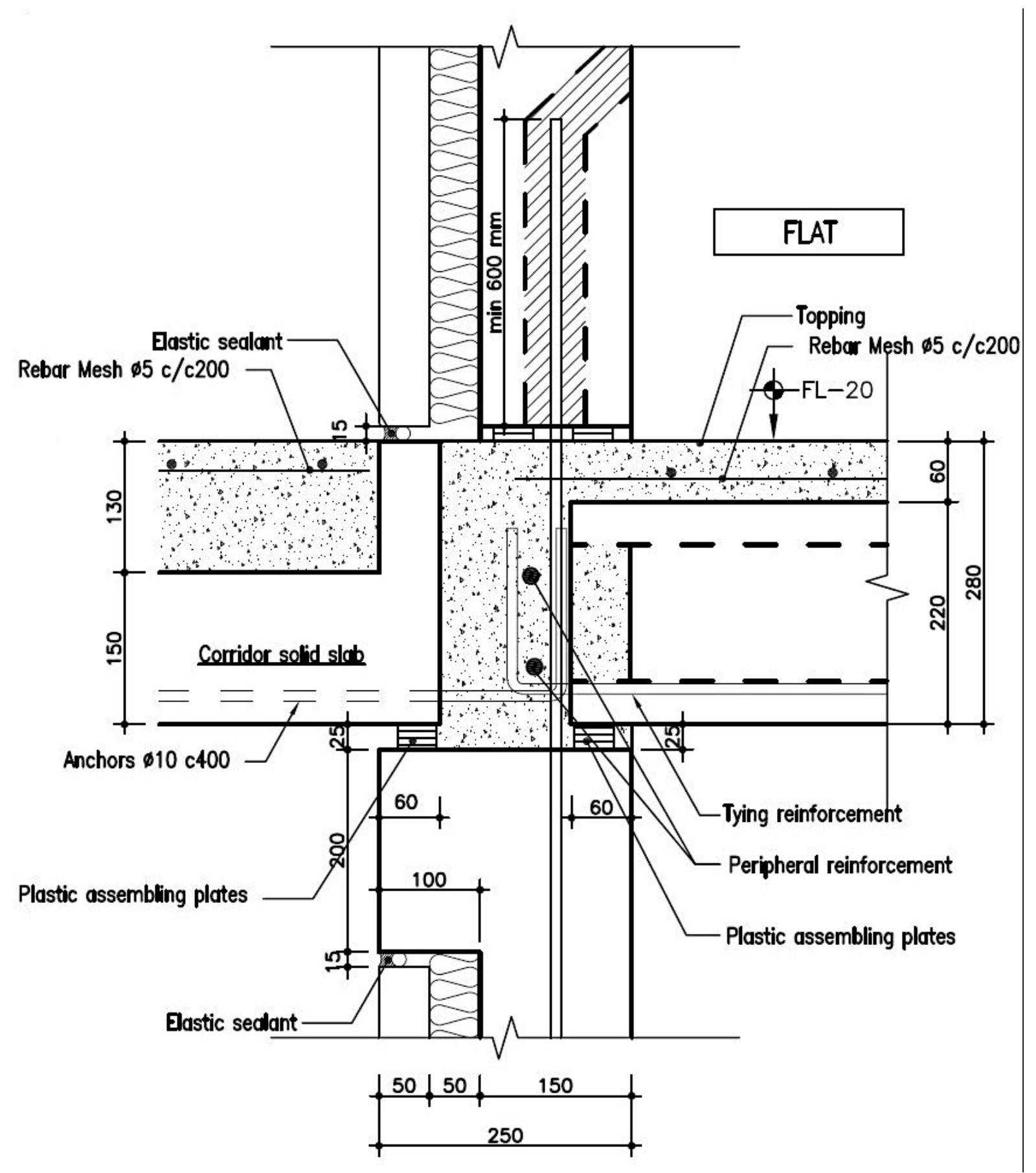

Figure 6. B - Longitudinal section showing the detail of the bonding point between the pre-cast structural pieces of both the ceiling and the wall and the simplified structural technique for bonding that helps achieve design flexibility [10] 


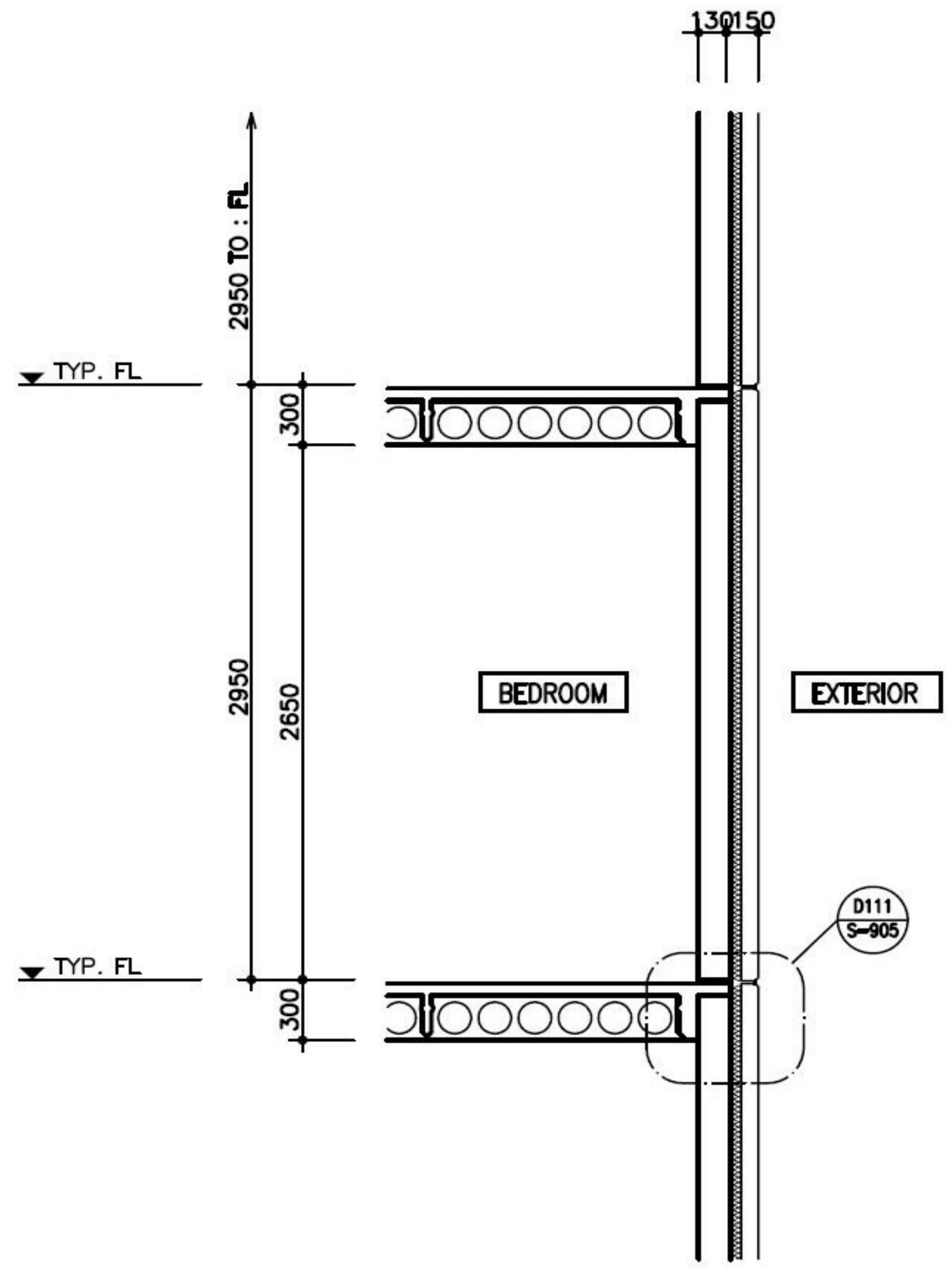

Figure 7. Units ready for the hollow core slab system in the Bismayah residential complex [10] 


\section{Results and Discussion}

\subsection{Detailed Analysis}

\subsubsection{The first main item (formal performance)}

A. The first sub-item (geometric shape of the housing unit)

The results showed the achievement of the possible values (the size and capacity of housing units, privacy) within the geometric shape of the housing unit (the highest degree of verification was $100 \%$ ). The Bismayah city project was distinguished by the proportion of housing units for residents, while providing sufficient privacy in the building units within the same sector.

B. The second sub-item (shape of the building block and facades).

The results showed the achievement of the possible values for the form of the housing unit assembly model, the design of the external envelope of the building, and building materials and colours, with an average rate of $66 \%$. The Bismayah complex is characterized by assembling residential buildings in an inward-oriented pattern, achieving a cluster (the central space).

\subsubsection{The second main item (functional performance)}

\section{A. The first sub-item (planning efficiency)}

The results of the job performance analysis showed the achievement of the possible values for the respectful design of the site characteristics, the design compatibility with the climate, and the design's link to the culture of the place $(91.6 \%)$. The design is in line with the site's topographic characteristics, respecting the site through its hierarchy. The design also conforms to the local climate in terms of the orientation of residential buildings and public buildings and the use of sunshade to protect from direct sunlight.

\section{B. The second sub-item (design efficiency)}

The results of the analysis of job performance for design efficiency showed the possible values for each of the design stage, the construction stage, and the operation stage, with a rate of $82.5 \%$. The building units are characterized by high design flexibility in the housing unit space by adopting a construction technique that helps raise the internal partitions without being restricted to the structural framework of the building as a whole (using digital modelling and proactive structural analysis with high performance). An effective participatory work environment and design also exists between different competencies. In addition, there is a decline in the origin's ability to sustain in the future and improve the evolutionary structure. Regarding the construction phase, the use of effective building and site management systems is evident. As for the operation stage, the residential complex works to preserve the infrastructure and maintain the safety and security of the facility.

\subsubsection{The third main item (environmental performance)}

A. The first sub-item (harmony with the local environment and climatic efficiency)

The results of the environmental performance analysis showed achieving the possible values of effective energy handling, effective materials handling, and water effective handling by $91 \%$, as the residential complex ensures the effective treatment of water and materials and energy reduction.

\subsubsection{The fourth main item (the economic and material aspect)}

\section{A. The first sub-item (economic)}

The results showed that the possible values of economic performance (reducing energy consumption and reducing construction costs) were achieved by $87.5 \%$ in terms of lowering construction costs and rates of construction wages and employment as well as reducing energy consumption.

\section{B. The second sub-item (physical)}

The possible values for the use of materials in construction (using building technology in formal manufacturing, studying the behaviour and properties of building materials, testing structural behaviour, structural strength and durability, and choosing an advanced building material) were an average of $93.5 \%$. This was achieved by implementing the project in a specific way (pre-cast concrete) and reducing production costs, as the project site was equipped with a sophisticated factory, the first of its kind in the Middle East, which achieves the highest structural strength with less weight and greater length.

\subsection{Overall Analysis}

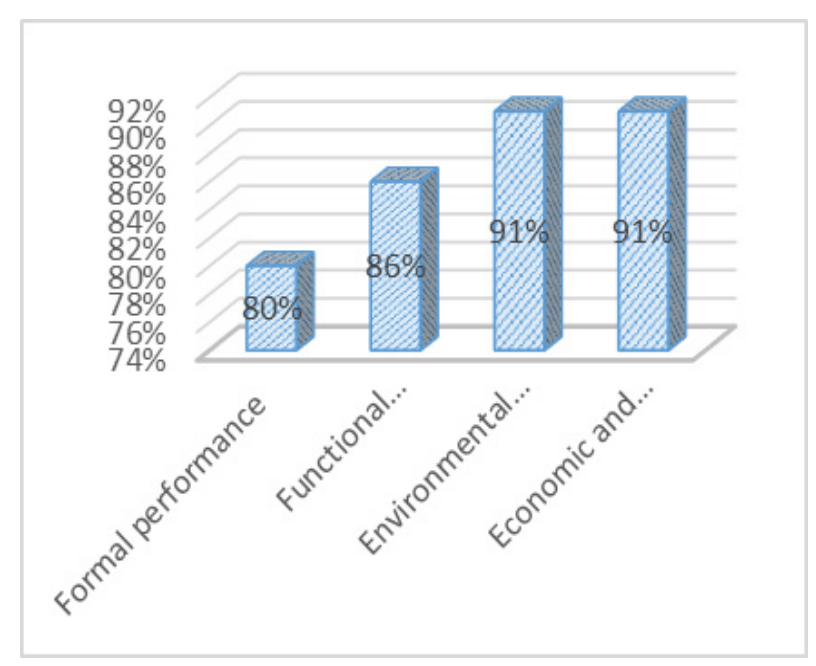

Figure 8. Performance percentages 
In general, based on the theoretical framework presented by the researchers, the results of the analysis showed that the residential complex achieved the following percentages for each item: official performance (80\%), job performance (86\%), environmental performance (91\%), and economic performance (91\%), as shown in Figure 8.

\section{Conclusions and Recommendations}

Construction technology is defined as the part related to the design of the structural fabric and it is based on (material technology, construction systems, construction time), which aim to develop an economy-based building industry that takes into account the human aspects of the population, and the architectural design in terms of sustainability standards, techniques and new design expertise.

Construction technology: Techniques help improve the performance of buildings by raising the following:

Formal performance: This is achieved by obtaining the aesthetic aspects at the design level (geometrical housing unit shape, building block shape, facades).

Functional performance: This is achieved by planning and design efficiency.

Environmental performance: This means the principles of sustainable housing design, including efficient energy, materials, and water use.

The results showed the superiority of the indicators and values of the specific elements of functional performance (planning efficiency, design efficiency) to achieve social sustainability because of their connection to the identity of the place through the technology of the construction system. They also showed the values of economic and material performance through efficient dealing with resources and reducing construction costs, which are achieved by using new construction system (Hollow Core Slab System) as well as the values of the formal performance (shape of the housing unit and shape of the values of environmental performance using harmony with the local environment and climate within the patterns applied to Bismayah city project).

The authors recommend expanding the use of contemporary construction manufacturing techniques that achieve efficient functional, formal, and economical characteristics as the ideal solution to the housing crisis in Iraq.

The authors recommend the scientific development of the capabilities of local engineers in the use of contemporary technological techniques such as digital modelling and digital fabrication at relevant institutions to enhance local architecture by creating architectural models different from traditional patterns.

The authors recommend conducting architectural laboratory research to study the properties of local materials and strength tests as well as digital modelling with BIM applications to raise physical and economic performance. 


\section{Appendix: Practical Application in Research Samples (Prepared by the Researchers)}

\begin{tabular}{|c|c|c|c|}
\hline \multicolumn{4}{|c|}{$\begin{array}{l}\text { Note: The weight assigned to the impact of each variable in the analysis is as follows: } 1=\text { weak impact, } 2=\text { medium impact, } 3=\text { good impact, } \\
\text { and } 4=\text { =strong impact. Note: The statistical equation to standardize the values of the indicators (percentage relative frequency) }\end{array}$} \\
\hline Main item & Sub-item & Code & Weight assigned to the impact of each variable \\
\hline \multirow{9}{*}{ X.1 } & \multirow{2}{*}{ X.1.1 } & X.1.1.1 & 4 \\
\hline & & X.1.1.2 & 4 \\
\hline & \multirow{2}{*}{\multicolumn{2}{|c|}{$(2 * 4=8)$}} & 8 \\
\hline & & & $100 \%$ \\
\hline & \multirow{3}{*}{ X.1.2 } & X.1.2.1 & 3 \\
\hline & & X.1.2.2 & 2 \\
\hline & & X.1.2.3 & 3 \\
\hline & \multirow{2}{*}{\multicolumn{2}{|c|}{$\left(3^{*} 4=12\right)$}} & 8 \\
\hline & & & $66 \%$ \\
\hline \multirow{2}{*}{\multicolumn{3}{|c|}{ Secondary singular effect value $(5 * 4=20)$}} & 16 \\
\hline & & & $80 \%$ \\
\hline \multirow{17}{*}{ X.2 } & \multirow{3}{*}{ X.2.1 } & X.2.1.1 & 4 \\
\hline & & X.2.1.2 & 4 \\
\hline & & X.2.1.3 & 3 \\
\hline & \multirow{2}{*}{\multicolumn{2}{|c|}{$(3 * 4=12)$}} & 11 \\
\hline & & & $91.6 \%$ \\
\hline & \multirow{10}{*}{ X.2.2 } & X.2.2.1 & 4 \\
\hline & & X.2.2.2 & 1 \\
\hline & & X.2.2.3 & 4 \\
\hline & & X.2.2.4 & 2 \\
\hline & & X.2.2.5 & 4 \\
\hline & & X.2.2.6 & 4 \\
\hline & & X.2.2.7 & 4 \\
\hline & & X.2.2.8 & 3 \\
\hline & & X.2.2.9 & 3 \\
\hline & & X.2.2.10 & 4 \\
\hline & \multirow{2}{*}{\multicolumn{2}{|c|}{$(10 * 4=40)$}} & 33 \\
\hline & & & $82.5 \%$ \\
\hline \multirow{2}{*}{\multicolumn{3}{|c|}{ Secondary singular effect value $(13 * 4=\mathbf{5 2})$}} & 45 \\
\hline & & & $86 \%$ \\
\hline \multirow{3}{*}{ X.3 } & \multirow{3}{*}{ X.3.1 } & X.3.1.1 & 3 \\
\hline & & X.3.1.2 & 3 \\
\hline & & X.3.1.3 & 4 \\
\hline \multirow{2}{*}{\multicolumn{3}{|c|}{ Secondary singular effect value $(3 * 4=12)$}} & 11 \\
\hline & & & $91 \%$ \\
\hline \multirow{9}{*}{ X.4 } & \multirow{2}{*}{ X.4.1 } & X.4.1.1 & 3 \\
\hline & & X.4.1.2 & 4 \\
\hline & \multirow{2}{*}{\multicolumn{2}{|c|}{$(2 * 4=8)$}} & 7 \\
\hline & & & $87.5 \%$ \\
\hline & \multirow{4}{*}{ X.4.2 } & X.4.2.1 & 4 \\
\hline & & X.4.2.2 & 4 \\
\hline & & X.4.2.3 & 4 \\
\hline & & X.4.2.4 & 3 \\
\hline & \multicolumn{2}{|c|}{$(4 * 4=16)$} & 15 \\
\hline & & & $93.5 \%$ \\
\hline \multirow{2}{*}{\multicolumn{3}{|c|}{ Secondary singular effect value $\left(\mathbf{6}^{*} 4=\mathbf{2 4}\right)$}} & 22 \\
\hline & & & $91 \%$ \\
\hline
\end{tabular}


[8] Fawcett R, Allison A, "Using modern methods of construction to build homes more quickly and efficiently", UK, 2005, pp 9. https://www.rics.org.

\section{REFERENCES}

[9] Davies A, "Modern Methods of Construction", 1st ed, the Royal Institution of Chartered Surveyors (RICS), 2018, pp. $18-21$.

[1] Merriam Webster, "Definition of technology", Archived from the original, web.archive.org. (accessed July. 2, 2020).

[2] Keith R, Paul C, Novakovic O, "A guide to modern methods of construction", The BRE Housing Innovation Centre, UK, 2006, pp 3,5,13.

[3] Neenu A, "Modern Methods of Construction Details and Applications", the constructor, 2018. www.theconstructor. org.

[4] Hannah M, Hunter, N, "Modern methods of construction", NHBC Foundation, 2018, pp 9-15.

[5] Shash A, Alawad M, " Modern Construction Methods (MMC) in Saudi Arabia: Evaluation Aspects and Barriers", Journal of Engineering and Architecture, Vol 8, no. 2, pp. 50-65, 2020. DOI: $10.15640 /$ jea.v8n2a8

[6] Sobeih Z, "Determinants of sustainable environment in high-density housing projects", Master Thesis, University of Baghdad, College of Engineering, Iraq, 2020, pp 87-90.

[7] Gitonga V, "Modern Methods of Construction to Build Homes More Quickly and Efficiently: A Study of the UK Industry", Embu University College, 2019, pp 17-19. DOI: 10.13140/RG.2.2.21757.51684

[10] Hanwha. E\&C, "Bismayah New City Architectural Drawings Book", Unpublished book, Iraq, 2010, pp 12, 25,31 .

[11] Hanwha Engineering \& Construction Copr, http://bismaya ha.org/ (accessed Jan. 1, 2022).

[12] Mahmood Y, Qais H, "Bismaya Residential Complex compatibility with the Iraqi Green Architecture Code", https://jpd.uobaghdad.edu.iq, (accessed Nov. 13, 2021).

[13] http://www.bismayah.org / Hanowa company official site.

[14] Alzidi M, Al-Samarae S, "Employing Smart Systems In Integrated Management Of Infrastructure For Housing Projects" The Iraqi Journal of Architecture and Planning, 2020, Vol. 19, no.2, Pages 72-87, DOI:10.36041/iqjap.v19 i2.518

[15] Gharavi Al, "Toward A Convergent Model of Flexibility In Architecture", Journal of Architecture and Urbanism, Vol.42, no2, pp 120-133, 2018, DOI:10.3846/jau.2018.62 41.

[16] Abu al Khalil I, "Modern Methods of Construction MMC \& Architecture Design", Al Benaa Magazine, Vol 6, no. 1, pp. $11,2020$. 